MANTHAN: Journal of Commerce and Management Volume 4, Issue 1, January-June 2017, pp. 51-64 doi: 10.17492/manthan.v4i01.9605

\title{
An Examination into the Link between Financial Inclusion, Financial Literacy and Investment Patterns
}

\author{
Swati Narula*
}

\begin{abstract}
A sound financial system is considered as the backbone of an economy. This holds true especially in a country like India where still a majority of the population is unbanked or "financially excluded". Research worldwide has pointed out that financial illiteracy is one of the major contributors of financial exclusion. The financially illiterate investor is unable to navigate the contemporary complex financial markets with ease. The financial environment in the world has undergone a tremendous change shifting much of the responsibility on the individuals to manage their finances and plan future well-being. Hence, the importance of acquiring financial literacy skills has grown manifolds. Due to this, financial literacy and financial inclusion has elicited much interest in the recent past in both developed and developing countries of the world. In this paper, an attempt has been made to identify level of financial literacy of the investors in Delhi. An investigation of the investment pattern of investors has also been done. Further, a nexus between financial literacy, financial inclusion and economic growth has also been investigated. In addition, the various efforts undertaken by the government of India and various other parties has also been discussed in detail.
\end{abstract}

Keywords: Economic Growth; Financial inclusion; Financial exclusion; Financial Literacy; Investment pattern; Financial system.

\subsection{Introduction}

Rangarajan Committee (2008) viewed financial inclusion as "The process of ensuring access to financial services and timely and adequate credit where needed by vulnerable groups such as weaker sections and low income groups at an affordable cost". Financial inclusion plays a predominant role in building a strong foundation of a country's financial infrastructure, which in turn facilitate its economic growth and development. Moreover, the absence of financial inclusion can lead to financial illiteracy

*Assistant Professor, Vivekananda Institute of Professional Studies, Guru Gobind Singh Indraprastha University, Delhi, India. (Email id: swati.fin@gmail.com) 
and the emergence of an unorganised financial sector such as indigenous banking, which is not warranted for in today's financial environment. Recently our honorable Prime Minister, Mr. Narendra Modi, launched the 'Pradhan Mantri Jan-DhanYojna' (a plan to provide financial services and bank accounts with no stipulation for maintaining a minimum balance in the account). However, merely opening of these bank accounts will not automatically yield economic growth. On the contrary, it may result in a burden of no-frill/dormant accounts, which is certainly not the objective of financial inclusion. Hence, there exists a dire need to evaluate the nexus between the financial inclusion and economic growth of any nation.

Few researchers suggest a positive and significant association between financial inclusion and economic growth. Notable amongst these is the seminal work of Walter (1873), Schumpeter (1912), McKinnon (1973), Gurley and Shaw (1955), and King and Levine (1993), Sharma (2016) and others. Their findings suggest that financial inclusion is a driver of economic growth. Although there is another school of thought whose proponents present a contradicting result on the direction of causality between financial inclusion and growth. Nonetheless, majority of researchers opined that financial inclusion and its various dimensions are major drivers of an economy. Therefore, the government and policy makers must look to address policy issues to foster economic growth through financial inclusion.

The process of growth, development and financial inclusion are interrelated. Provision of financial services to poor and weaker section can bring benefits for poverty reduction and growth. According to a study by Burgess and Pande (2005), it was established that a one per cent increase in the number of rural bank branches led to drop in poverty of $0.34 \%$ and increase in output of $0.55 \%$. This was mainly because access to finance made it easier for poor people to diversify out of agriculture. Access to financial services also limits some risk such as holding money in bank reduces risk of loss through fire or theft. Thus, Financial Inclusion is an enabler and accelerator of economic growth, job creation and development.

\subsection{Definition of financial literacy}

Financial literacy is the ability to understand how money works in the world: how someone manages to earn or make it, how that person manages it, how he/she invests it (turn it into more) and how that person donates it to help others. More specifically, it refers to the set of skills and knowledge that allows an individual to make informed and effective decisions with all of their financial resources. The Organization for Economic Co-operation and Development (OECD) started an inter-governmental project in 2003 with the objective of providing ways to improve financial education and 
literacy standards through the development of common financial literacy principles. In March 2008, the OECD launched the International Gateway for Financial Education, which aims to serve as a clearinghouse for financial education programs, information and research worldwide. In UK, the alternative term "financial capability" is used by the state and its agencies: the Financial Services Authority (FSA) in the UK started a national strategy on financial capability in 2003. The US Government also established its Financial Literacy and Education Commission in 2003. Financial Literacy is known as the knowledge and ability of an individual to make informed and effective money management decision. Financial literacy can be achieved when a person develops financial knowledge and skill along with access to financial services, government policy, financial instruments and updates in tax structure.

The term financial literacy is used often but many do not truly understand the definition. As Stone et al. (2008) states, "financial literacy is the ability to read, analyse, manage and communicate about the personal financial conditions affecting material wellbeing" (p. 1). The concept of financial literacy is taking into consideration the ability to balance your check book or being able to read your financial statements. A better informed citizen can be more prudent in planning his personal finance consequently helps in strengthening the country's economy. It is important that people should accurately perceive their own economic decision Therefore there should be substantial contribution from government of India and other non- government organizations.

\subsection{The Indian Scenario}

In India, 65\% Indians lack financial literacy, according to Financial Service giant Visa, which recently came up with a survey that declared India as one of the least financial literate countries among 28 countries. This survey is conducted in the period between February and April 2012 and interviewed 25,500 respondents in 28 countries including global superpowers like USA, Canada and Australia. Out of a maximum possible score of 100, Brazil topped the charts with a 50.4 followed by Mexico with 47.8, Australia with 46.3, USA with 44 and Canada with 43.8 in top 5 overall country ranking. India ranked 23rd as the report termed only $35 \%$ of Indian respondents as financially literate. In India, the Reserve Bank of India launched a first initiative in 2007 to establish Financial Literacy and Credit counselling centres throughout the country which would offer free financial education and counselling to urban and rural population The major initiatives that have been taken by various agencies to enhance financial capability of Indian population have been discussed below. 
54 | MANTHAN: Journal of Commerce and Management, Volume 4, Issue 1, Jan-Jun 2017

\subsection{RBI's initiative on financial literacy}

Reserve Bank of India has undertaken a project called "Project Financial Literacy" whose main objective is to propagate information regarding the general banking concepts to various target groups, including school and college students, women, rural and urban poor, defence personnel and senior citizens. The project has been designed to be implemented in two modules, one module focusing on the economy, RBI and its activities, and the other module on general banking. The material is created in English and other vernacular languages. The information is distributed to banks, local government, schools and colleges through presentations, pamphlets, brochures, films and also through RBI's website. The other measures implemented by Reserve Bank of India in this regards include conducting essay competition to promote financial awareness among school children on topic banking and finance. Recently RBI launched 'RBI Young Scholars' award' scheme for outstanding students in order to generate interest in creating awareness of banking sector of the country.

\subsection{SEBI's initiative on financial literacy}

Securities Exchange Board of India has started financial education on a nationwide scale. To undertake financial education to various target segments viz. school students, college students, working executives, middle income group, home makers, retired personnel, self-help groups etc., SEBI has empanelled Financial Educator Resource Persons throughout India. The Resource Persons are given training on various aspects of finance and equipped with the knowledge about the financial markets. These SEBI Certified Resource Persons organise workshops to these target segments on various aspects viz. savings, investment, financial planning, banking, insurance, retirement planning etc. More than 3500 workshops have been already conducted in various states covering around two lakh and sixty thousand participants. Investor education programs are conducted by SEBI through investor associations all over the country.

Regional seminars are conducted by SEBI through various stakeholders viz. Stock Exchanges, Depositories, Mutual Funds Association, Association of Merchant Bankers etc. SEBI has a dedicated website for investor education wherein study materials are available for dissemination. SEBI also publishes study materials in English and vernacular languages. Under 'Visit SEBI' programme, School and college students are encouraged to visit SEBI and understand its functioning. SEBI has recently set up SEBI Helpline in 14 languages wherein through a toll free number, investors across the country can access and seek information for redressal of their grievances and guidance on various issues. (ref.www.rbi.org) 


\subsection{IRDA'S initiatives on financial education}

Insurance Regulatory and Development Authority has taken various initiatives in the area of financial literacy. Awareness programmes have been conducted on television and radio and simple messages about the rights and duties of policyholders, channels available for dispute redressal etc. have been propagated through television and radio as well as the print media in English, Hindi and 11 other Indian languages. IRDA conducts an annual seminar on policy holder protection and welfare and also partially sponsors seminars on insurance by consumer bodies. IRDA has done a pan India survey on awareness levels about insurance. IRDA has also brought out publications of 'Policyholder Handbooks' as well as a comic book series on insurance. A dedicated website for consumer education in insurance has been launched.

\subsection{PFRDA initiatives on financial education}

The Pension Fund Regulatory and Development Authority, India's youngest regulator has been engaged in spreading social security messages to the public. PFRDA has developed FAQ on pension related topics on its web, and has been associated with various non-government organizations in India in taking the pension services to the disadvantaged community. PFRDA has issued advertisements in print media and electronic media through radio and television. PFRDA appointed intermediaries are called Aggregators who are directly responsible for pension awareness mostly in vernacular languages and in line with socio-economic sensibilities.

\subsection{Market players' initiatives on financial education}

Commercial banks are realising that they are missing out on large segment of financially illiterate and excluded segment of prospective customers. Major financial institutions are spreading awareness through Financial Literacy and Counselling Centres and Rural Self Employment Training Institutes on financial literacy. The objective of these centres is to advise people on gaining access to the financial system including banks, creating awareness among the public about financial management, counselling people who are struggling to meet their repayment obligations and help them resolve their problems of indebtedness, helping in rehabilitation of borrowers in distress etc. Some of these credit counselling centres even train farmers/women groups to enable them to start their own income generating activities to earn a reasonable livelihood. Similarly, many Stock Exchanges, Broking Houses and Mutual Funds have initiatives in the field of financial education through conducting of seminars, issuance of do's and don'ts, and newspaper campaigns. Insurance companies too, carry out campaigns and other educational activities for generic education in insurance. 
56 | MANTHAN: Journal of Commerce and Management, Volume 4, Issue 1, Jan-Jun 2017

\subsection{Other Measures}

Other than the Reserve Bank of India and other regulators, various NGO's in the country are also spreading financial literacy in the country. 'Sanchayan' is a NGO dedicated exclusively to spreading financial literacy and awareness among the youth and adults from low-income background. 'Sanchayan' conducts free workshops for the underprivileged youth on topics ranging from the basics of banking, credit cards and PAN cards to the investing in shares and mutual funds, so that these youth can become financially aware and also a part of the mainstream banking and financial services industry. Indian School of Microfinance for Women through its Citi Centre for Financial Literacy (CCFL) has formed a network of partner organizations named National Alliance for Financial Literacy (NAFil) to take financial literacy as a movement across the country. Also Manndeshi Udyogini Business School for Rural Women: HSBC has collaborated with Mann Vikas Samajik Sanstha in Satara to provide financial literacy and management skills to girls and women with no formal education.

\subsection{Literature Review}

This section reviews some major studies that have examined the financial literacy levels and factors governing it. Gowri (2006) assessed the level of financial literacy among the young employees in Coimbatore city. Financial literacy was found to be highly influenced by age, region or country in which the individual resides, the level of income, socio demographic factors like his family, number of dependents, mother's education, financial advice etc. Dhillon (2007) investigated the impact of financial literacy on Individual's financial decision and how much impact gender and age differences have on the level of financial literacy with specific reference to Delhi/NCR region. The author concluded that the level of financial literacy among individuals is low, so there is a need to increase financial literacy and both public and private sector should step in and take initiatives in order to improve the level of financial literacy.

Bhabha et al. (2010) stated financial literacy of working women in developing countries as an important factor which affects the saving-investment behaviour of female workforce in developing countries like Pakistan. Habschick, Britta, and Evers (2007) investigated how financial literacy education affects the behaviour, financial decisions, and use of financial products by rural households in India. The findings clearly indicated that there was a severe lack of understanding of formal financial products related information. Kumar (2012) analysed the influence of the financial literacy level on individual investment decisions. The study was also done on the information sources or channels through which the individuals decide their investment on a particular 
investment product. Findings showed except the gender, there was a relationship between the socio-economic factors and the level of financial literacy possessed by the respondents.

Bhushan (2014) examined the awareness level and investment behaviour of salaried individuals towards financial products. For the purpose of research, the researcher had taken Himachal Pradesh as an area of study. The researcher concluded that respondents were quite aware about traditional and safe financial products whereas awareness level of new age financial products among the population was low. Ibrahim and Alqaydi (2013) examined financial literacy among a sample of individuals residing in the United Arab Emirates (UAE) and its relation to different forms of personal debt. The results indicated that the average level of financial literacy in UAE (0.433) is statistically significantly below the average level reported in the literature (about 0.50 ). However, there were no significant differences between the mean score of males and females. The author indicated that individuals with strong financial attitude tend to borrow less from credit cards.

Aggarwal (2014) evaluated the influence of various demographic factors like gender, discipline and level of qualifications on financial literacy. The level of education and discipline (commerce) was found to have a positive influence on financial literacy. Males were found to have higher levels of financial awareness as compared to females. Sharma (2016) validated the finance-growth nexus in relation to financial inclusion and economic growth in the emerging Indian economy during 2004-2013. The author used the VAR model and Granger causality analysis to reveal bidirectional causality between geographic outreach and economic growth, and unidirectional causality between the number of deposit/ loan accounts and GDP although no causality was found between the usage of banking services and economic prospects.

Although a plethora of studies have been conducted with regard to financial literacy in developed nations, the numbers of studies in context of developing nations are minimal. Moreover, through extensive survey of literature, it has been found that no major attempt has been made to quantitatively measure the financial literacy level of the investors on parameters of financial knowledge, financial attitude and financial behaviour which has been done in this study.

\subsection{Objectives and Scope of the Study}

The main objectives of the study are as follows:

(i) To measure the financial literacy level of retail investors of Delhi;

(ii) To study the investment pattern of retail investors of Delhi; 
(iii) To examine whether there is any significant difference between male and female financial literacy level; and

(iv) To identify the various financial literacy initiatives undertaken by government and non-government agencies.

The scope of the study is limited to the financial literacy level of 100 retail investors residing in Delhi region. Moreover, to determine the investment pattern of retail investors, 10 investment avenues are considered.

\subsection{Research Methodology}

This study is descriptive in nature. Both primary and secondary data have been collected in this study. Primary data is collected through a survey. The survey is carried out by means of self-administered, structured questionnaire and secondary data is collected from articles, research papers of various journals. In addition, t-test is used to assess the significant difference between male and female financial literacy level. Average mean has been calculated to analyse the mean rank of different investment options. A summary of research methodology has been provided in Table 1 .

Table 1: Summary of Research Methodology

\begin{tabular}{|l|l|}
\hline Research Design & Descriptive \\
\hline Population & Individuals residing in Delhi \\
\hline Sample Size & 100 \\
\hline Study approach & Survey Method \\
\hline Instrument Used & Structured Questionnaire \\
\hline Data Type & Primary and Secondary \\
\hline Sampling Type & Convenience Sampling \\
\hline
\end{tabular}

\subsection{Hypotheses of the study}

The following are the study hypotheses:

$\mathrm{H}_{01}=$ There is no significant difference between male and female financial literacy score.

$\mathrm{H}_{\mathrm{a} 1}=$ There is a significant difference between male and female financial literacy score.

$\mathrm{H}_{02}=$ There is no relationship between financial literacy and investment pattern.

$\mathrm{H}_{\mathrm{a} 2}=$ There is a relationship between financial literacy and investment pattern.

\subsection{Data Presentation and Analysis}

\subsection{Demographic profile of respondents}

Out of the total 100 respondents, the male respondents were 62 and the female respondents were 38 . The single respondents were 44 , married respondents were 53 and 
separated were 3 . The majority of the respondents i.e. 37 were private sector employee, followed by 35 self-employed, 10 were unemployed, 9 were public sector employee, 8 were not working and 1 was retired. Most of the respondents i.e. 50 were graduates, followed by 39 who were post graduates, 7 completed secondary school and mere 4 were M.Phil./Ph.D (Table 2).

Table 2: Demographic Profile of Respondents

\begin{tabular}{|l|c|}
\hline \multicolumn{1}{|c|}{ Particulars } & Number of Respondents \\
\hline Gender & 62 \\
\hline Male & 38 \\
\hline Female & 7 \\
\hline Educational Qualification & 50 \\
\hline Secondary School & 39 \\
\hline Graduate & 4 \\
\hline Post Graduate & \\
\hline M.Phil/Ph.D & 44 \\
\hline Marital Status & 53 \\
\hline Single & 3 \\
\hline Married & \\
\hline Separated & 35 \\
\hline Occupation & 10 \\
\hline Self Employed & 9 \\
\hline Unemployed & 37 \\
\hline Public Sector Employee & 1 \\
\hline Private Sector Employee & 8 \\
\hline Retired & \\
\hline Not Working & \\
\hline
\end{tabular}

\subsection{Financial literacy score}

Maximum respondents belong to medium level of financial literacy representing 76 respondents of the sample, followed by high level of financial literacy representing 17 respondents of the sample and then low level of financial literacy level representing 7 respondents of the sample (Table 3 ).

\subsection{Hypotheses testing}

Hypothesis 1

$\mathrm{H}_{01}=$ There is no significant difference between male and female financial literacy score. $\mathrm{H}_{\mathrm{a} 1}=$ There is a significant difference between male and female financial literacy score. 
60 | MANTHAN: Journal of Commerce and Management, Volume 4, Issue 1, Jan-Jun 2017

Table 3: Financial Literacy Score of Respondent

\begin{tabular}{|c|c|}
\hline Interval & Number of respondents \\
\hline $15-30$ & 7 \\
\hline $30-45$ & 76 \\
\hline $45-60$ & 17 \\
\hline
\end{tabular}

Table 4 indicates that the mean score of males is 40.32 and mean score of females is 39.58 . Additionally it indicates that the significance value is 0.571 which is more than threshold limit of 0.05 . This implies that we accept the null hypothesis indicating that there is no significant difference between the financial literacy level of males and females.

Table 4(a): Group Statistics

\begin{tabular}{|c|c|c|c|c|}
\hline Gender & N & Mean & $\begin{array}{l}\text { Standard } \\
\text { deviation }\end{array}$ & Standard error \\
\hline Financial Literacy Score & 62 & 40.3226 & 6.62032 & 0.84078 \\
\hline Males & 38 & 39.5789 & 5.85700 & 0.95013 \\
\hline Females &
\end{tabular}

Table 4(b): t-test Results (Independent Samples Test)

\begin{tabular}{|c|c|c|c|c|c|c|c|c|c|}
\hline & \multicolumn{2}{|c|}{$\begin{array}{c}\text { Levine's test } \\
\text { for equality } \\
\text { of variance }\end{array}$} & \multicolumn{7}{|c|}{ t-test for equality of means } \\
\hline & \multirow[t]{2}{*}{$\mathbf{F}$} & \multirow[t]{2}{*}{ Sig } & \multirow[t]{2}{*}{$\mathbf{t}$} & \multirow{2}{*}{\multicolumn{2}{|c|}{$\begin{array}{c}\text { df } \\
\text { Sig. (2-tailed) }\end{array}$}} & \multirow[t]{2}{*}{ M.D. } & \multirow[t]{2}{*}{ S.E.D. } & \multicolumn{2}{|c|}{$\begin{array}{c}95 \% \text { Confidence } \\
\text { interval }\end{array}$} \\
\hline & & & & & & & & Lower & Upper \\
\hline $\begin{array}{l}\text { FLS } \\
\text { Equal } \\
\text { Variance } \\
\text { assumed }\end{array}$ & .463 & .498 & .569 & 98 & .571 & .74363 & 1.30678 & -1.849 & 3.33689 \\
\hline $\begin{array}{l}\text { Equal } \\
\text { Variance } \\
\text { not } \\
\text { assumed }\end{array}$ & & & .586 & 85.744 & .559 & & 1.26872 & -1.778 & 3.26588 \\
\hline
\end{tabular}

\section{Hypothesis 2}

$\mathrm{H}_{01}=$ There is no relationship between financial literacy and investment pattern.

$\mathrm{H}_{\mathrm{a} 1}=$ There is a relationship between financial literacy and investment pattern. 
From Table 5, it could be inferred that low financial literacy level investors preferred mutual funds as the best means of investment because the mean rank value was 5.28 and moderate financial literacy level investors were more inclined towards savings and had mean rank score of 5.16 while investors with high financial literacy level opted for real estate with the mean rank of 4.47. Real estate which is considered risky avenue and requires high investment has been preferred by individuals having high financial literacy level. It could be clearly seen that investment decision varies with respect to financial literacy; hence we reject the null hypothesis and conclude that there is a relationship between financial literacy and investment pattern.

Table 5: Mean Rank for Different Investment Options

\begin{tabular}{|l|c|c|c|}
\hline Factors & $\begin{array}{c}\text { Mean rank of low } \\
\text { financial literacy } \\
\text { level }\end{array}$ & $\begin{array}{c}\text { Mean rank of } \\
\text { medium financial } \\
\text { literacy level }\end{array}$ & $\begin{array}{c}\text { Mean rank of high } \\
\text { financial literacy } \\
\text { level }\end{array}$ \\
\hline Bank Deposits/FD & 3.5 & 3.15 & 3.29 \\
\hline LIC & 4.00 & 2.28 & 4.00 \\
\hline PPF & 4.42 & 3.15 & 2.91 \\
\hline Bonds & 3.14 & 2.55 & 3.72 \\
\hline Shares & 3.11 & 5.16 & 2.18 \\
\hline Mutual Funds & 5.28 & 4.23 & 3.25 \\
\hline Gold/Silver & 4.00 & 2.15 & 3.15 \\
\hline Real Estate & 2.78 & 3.49 & 4.47 \\
\hline Post Office Scheme & 3.72 & 4.36 & 2.56 \\
\hline Others & 1.25 & - & - \\
\hline
\end{tabular}

\subsection{Conclusion}

The major findings of the study can be summarised as follows:

(i) It was found that the overall financial literacy level of the respondents was medium as out of 100 respondents 76 were in the range of medium level of financial literacy.

(ii) The study revealed that investors with high level of financial literacy preferred Real Estate, medium term level of financial literacy preferred shares and low level of financial literacy preferred mutual funds. The primary benefit looked by them was found to be future benefits and they preferred their own experience as the source of information.

(iii) It was found that the value of t-test was .569 and significance value was 0.571 which showed that there is no difference between male and female financial literacy. 
(iv) It was found that financial literacy and investment decisions are related because investors of different level of financial literacy preferred different investment option, source of information and type of information for their investment decisions.

(v) There are a lot of initiatives undertaken by government and various other parties for promoting financial literacy and financial inclusion. Still, a lot needs to be done.

\subsection{Limitations of the study}

The major limitation of the study was that the sample size was restricted to 100 only which acted as a constraint. Further, the study is limited to Delhi only and result may differ if conducted in other regions. Evaluation is based on the primary data generated through questionnaire and accuracy of the findings entirely depends on the accuracy of such data and unbiased responses of the customers.

\subsection{Scope for further research}

This study has investigated relationship between the demographic factors and financial literacy, and difference in personal investment decision for different time period. This study was limited to Delhi investors with only 100 respondents, so further studies can be done as extension of the same study with large number of respondents or for different states of India. Other studies can also focus on different factors like attitude of the investors towards financial literacy.

\subsection{Recommendations}

Financial literacy in India is on the positive side now. A majority of respondents had not only shown better skills in managing their financial budget but were also confident of facing any financial impediments in future. All these developments could be attributed as a result of initiatives taken by the Reserve bank of India, SEBI, NSE, commercial banks, NGO's, SHG's and the government. But the negative side of these was according to the ING consumer resourcefulness survey $98 \%$ of Indian citizens still do not have a demat account. The country where $48 \%$ of the population still lives on day to day earnings cannot dream of savings and life insurance. However these inequalities could be overcome if more and more enthusiastic and coordinated efforts are launched by the aforesaid agencies who are party to financial sector of the country. In this context, the following recommendations are noteworthy to increase the financial literacy of the country.

(i) Financial Education should be providing at secondary and senior secondary level of education as it was found financial literacy and educational level was related. 
(ii) Government should support financial literacy programs and schemes as it was found that such programs and scheme help investors in improving their financial literacy.

(iii) Global guidelines and standards for financial literacy initiatives and consumer protection frameworks in financial markets should be formulated.

(iv) Campaigns for spreading awareness about financial inclusion and financial literacy need to be intensified. This can be done through innovative dissemination channels including films, documentaries, pamphlets and road shows. Stakeholders, including the regulators and policy makers, may launch large scale awareness programmes.

\section{References}

Aggarwal, R. (2014). Financial inclusion in India: Challenges and opportunities. International Journal of Research, 1(4), 557-567.

Bhabha, J. I., Khan, S., Q., Qamar, A., Naeem, A. \& Khan, I. (2014). Impact of financial literacy on saving: Investment behaviour of working women in developing countries. Research Journal of Finance and Accounting, 5(13), 118-122.

Bhushan, P. (2014). Insights into awareness level and investment behavior of salaried individuals towards financial products. International Journal of Engineering, Business and Enterprise Applications, 8(1), 53-57.

Habschick, M., Britta, S., \& Evers, J. (2007). Survey of financial literacy schemes in the EU27. Hamburg: Evers-Jung, Financial Services Research and Consulting. Retrieved from http://ec.europa.eu/internal_market/finservices-retail/docs/capability/report_survey _en.pdf

Burgess, R. \& Pande, R. (2005). Do rural banks matter? Evidence from the Indian social banking experiment. The American Economic Review, 95(3), 780795.

Dhillon, L. K. (2007). Measuring financial literacy with specific reference to Delhi/NCR region. International Journal of Research in IT, Management and Engineering, 3(6), 1332. 
64 | MANTHAN: Journal of Commerce and Management, Volume 4, Issue 1, Jan-Jun 2017

Gowri, M. (2006). A study on financial literacy among young employees in Coimbatore city. Retrieved from http://www.grgsms.ac.in/wp-content/uploads /2014/03/Gowri-WP201403001.pdf

Gurley, J. G., \& Shaw, E. S. (1955). Financial aspects of economic development. The American Economic Review, 45(4), 515-538.

Ibrahim, M. E., \& Alqaydi, F. R. (2013). Financial literacy, personal financial attitude, and forms of personal debt among residents of the UAE. International Journal of Economics and Finance, 5(7), 126-138.

King, R. G., \& Levine, R. (1993). Finance and growth: Schumpeter might be right. The Quarterly Journal of Economics, 108(3), 717-737.

Kumar, K. S., Vijayabanu, C., \& Amudha, R. (2012). A case study on investors' financial literacy in Indian scenario. Journal of Applied Economic Sciences, 7(3), 262269.

McKinnon, R. I. (1973). Money and capital in economic development., Washington, DC: Brookings Institution Press.

Rangarajan, C. (2008). Report of the Committee on Financial Inclusion. Government of India.

Schumpeter, J. A. (1934). The theory of economic development. Cambridge, MA: Harvard University Press.

Sharma, D. (2016). Nexus between financial inclusion and economic growth: Evidence from the emerging Indian economy. Journal of Financial Economic Policy, 8 (1), 1-27.

Stone, D. N., Wier, B., \& Bryant, S. M. (2008). Reducing materialism through financial literacy. The CPA Journal, 78(2), 12-14.

Walter, B. (1873). Lombard street: A description of the money market. London: Henry S. King and Co. 